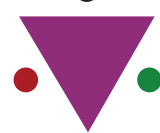

IJCRR

Section: Healthcare Sci. Journal Impact Factor: 6.1 (2018) ICV: 90.90 (2018)

Scopus'

\section{Role of Physiotherapist to Promote Physical Activity in Physical Therapy Settings: Questionnaire Study}

\section{Shweta A. Panchbudhe ${ }^{1}$, Y Praveen Kumar ${ }^{2}$, Sachin Choudhary ${ }^{3}$, Anjalee Chiwhane ${ }^{4}$}

\begin{abstract}
'Assistant Professor, Department of Cardio Respiratory Sciences Datta Meghe College of Physiotherapy, Nagpur-441110; 'Professor, Department of Cardio Respiratory Sciences, VSPM'S College of Physiotherapy, Nagpur-441110; Nice Principal, Department of Cardiorespiratory Sciences Datta Meghe College of Physiotherapy, Nagpur-441110; 4Professor Department of General Medicine Jawaharlal Nehru Medical College, Datta Meghe Institute of Medical Sciences Sawangi, Wardha-442001.
\end{abstract}

\title{
ABSTRACT
}

Background: Physical inactivity is a major risk factor for chronic disease. Primary health care practitioners are well placed to promote a physically active lifestyle. The perceptions and practice of physical therapists on their role in physical activity promotion are not well known.

Objectives: The aim of the study is to determine the promotion of physical activity in physical therapy settings and to know the attitude of the therapist towards physical activity in relation to patient. The objective of this study was to determine the knowledge, confidence, role perception, barriers, feasibility, and counseling practice of physical therapists and physical therapist students

Materials and Methods: Physiotherapist both male and female within the age group of 25-34 years who are clinically practicing either in physiotherapy college or private clinics who are handling patients on day to day basis irrespective of type of patients handled will form the subjects for this study.

Results: The first questions revealed that $61 \%$ of the therapist reportedly encouraged patients to have physical active lifestyle in almost about 6-9 patients, moreover none of the therapist answered the answers in never or rarely. $51 \%$ of the therapist agreed that taking stairs at work is enough physical active to improve wealth as shown. the results for half an hour of walking on most days is all the exercise that is needed for good health has been agreed by $54 \%$ of physiotherapist. Exercise that is good for health must make you puff and pant has been disagreed by $44 \%$ of the subjects and $10 \%$ have strongly disagreed. $44 \%$ have agreed from the survey that several short walks of 10 minutes is better than one round of long walk per week for good health. Discussing the benefits of physically active lifestyle with patients is a part of physical therapist role have been agreed by $81 \%$. Suggesting patients ways to increase daily physical activity is a part of physical therapists role have been agreed by $83 \%$ of the subjects. Only $76 \%$ felt confident in giving general advice to patients on physically active lifestyle. $73 \%$ of subjects were agreed to feel confident in suggesting specific activity programmes for their patients. overwhelming $100 \%$ agreement was found for fact that physical therapist should be physically active to act as a role model for their patients of which $91 \%$ strongly agreed and $9 \%$ agreed. About own physical activity $54 \%$ felt much more active when compared with other Indians of same age and sex. $39 \%$ felt slightly more active and $7 \%$ about the same. none of them reported with slightly less active or much less active.

Conclusion: It is concluded that physiotherapist are basically responsible for encouraging patient for having physically active and also suggest various measures to improve and enhances patients physical active ,therefore this study highlight tens the fact that physical therapy not only involves administration of physical exercise but includes advices and means of physical activity promotion.

Key Words: Questionnaire, Physiotherapy students, Physical therapy

\section{INTRODUCTION}

Physical activity is accepted worldwide as a public health priority. A physically active lifestyle has been shown to significantly reduce the risk of developing cardiovascular disease, obesity, type 2 diabetes mellitus, several forms of cancer, and depression. Physical therapists are primary care practitioners who are thought to have great potential for physical activity promotion. ${ }^{1}$ They prescribe exercise for a wide range of conditions (mostly musculoskeletal) requiring

\section{Corresponding Author:}

Dr. Shweta A. Panchbudhe, Assistant Professor, Dept of Cardiorespiratory, Sciences Datta Meghe College of Physiotherapy, Nagpur. E-mail shweta12panchbudhe@gmail.com

ISSN: $2231-2196$ (Print)

Received: 21.05 .2020
ISSN: 0975-5241 (Online)

Revised: 14.06 .2020
Accepted: 27.06 .2020
Published: 21.07 .2020 
rehabilitation. Currently, physical therapy is mainly a tertiary prevention discipline, even though physical therapists are equipped with the ideal skills and potential to act in a primary prevention role. In the United States, a survey of physical therapists indicated that increasing physical activity was the most frequent area of focus for health promotion behavior. The physical therapists' confidence in prescribing nontreatment physical activity programs is the best predictor of whether physical activity is prescribed. physical therapists prescribed physical activity for conditions other than musculoskeletal conditions ${ }^{1}$

To promote and maintain health, all healthy adults aged 18 to $65 \mathrm{yr}$ need moderate-intensity aerobic (endurance) physical activity for a minimum of $30 \mathrm{~min}$ on five days each week or vigorous-intensity aerobic physical activity for a minimum of $20 \mathrm{~min}$ on three days each week ${ }^{2}$. Frequent physical activity is an important behavior for individual and population health. To promote and maintain health, all healthy adults need to engage in moderate-intensity aerobic physical activity for a minimum of 30 minor vigorous-intensity aerobic activity for a minimum of $20 \mathrm{~min}^{2}$

\section{METHODOLOGY}

\section{Selection criteria}

Physiotherapist both male and female within the age group of 25-34 years of age.

who are clinically practicing either in physiotherapy college or private clinics.

who are handling patients on day to day basis irrespective of type of patients handled will form the subjects for this study.

\section{Inclusion criteria}

The inclusion criteria of the study were as follows:

- Bachelors of physiotherapy

- Masters of physiotherapy

- Those pursuing with masters of physiotherapy

- Age 25-34 years

\section{Exclusion criteria}

The exclusion criteria of the study were as follows:

- Students of BPTh

- Interns

- Physical assistants

- Less than 25 years and more than 34 years

\section{Sample size: 100}

\section{Material used}

Standard semi structured following questionnaire
The questionnaire contained 5 components

1. Knowledge about the amount of physical activity required for the health benefits in adults

2. Perception of the role of physical therapist in physical activity promotion

3. Confidence in promoting physical activity

4. Barriers of physical activity promotion

5. Feasibility of different physical activity promotion strategies

\section{Survey design}

The survey questionnaire were adapted from a previous survey questionnaire used in a study titled" Physical activity promotion in the physical therapy setting: perspective from practitioners and students"1 and all the items were scored on 5 point Likert scale. The questionnaire covered the following topics: Knowledge about the amount of physical activity required for health benefits in adults ( 4 items), Perception of the role of physical therapist in physical activity promotion ( 2 items),Confidence in promoting physical activity ( 3 items),Barriers to physical activity promotion ( 6 items),and Feasibility of different physical activity promotion strategies (4 items)

\section{Procedure}

Permission to carry out the research were taken from the ethical committee of the Datta Meghe college of Physiotherapy, Nagpur.

According to the inclusion criteria the physiotherapist who were voluntarily willing to participate in the survey were selected from various physiotherapy clinics and few sample were taken from the same institution

The aim and protocol of the study was described to the therapist and their written consent were obtained. On the same day , researcher handed over the questionnaire to the therapist, and requested then to tick in the appropriate boxes of the questionnaire according to their most suitable answers.

A stipulated time of 10-15 minutes were given to them to fill the questionnaire and were asked to hand over the questionnaire to the researcher within the time limit. The questionnaire contained 5 component and the therapist were requested to answer all the questions.

The questionnaire was simple but even if the therapist face any problem while filling the questionnaire, the researcher was explain it and solve the problem. The questions which were unticked and which contained any other marking other than tick,those questionnaire were not included for data analysis 


\section{RESULTS}

\section{TABLE NO 1}

Que 1: How often did you encourage your patient to have more physical active lifestyle?

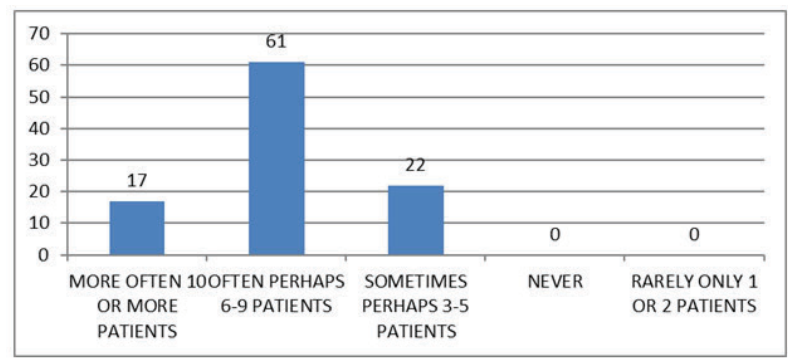

Table no 1 shows the answer of the first questions revealed that $61 \%$ of the therapist reportedly encouraged patients to have physical active lifestyle in almost about 6-9 patients, moreover none of the therapist answered the answers in never or rarely

\section{TABLE NO 2}

Que 2: Taking the stairs at work is enough physical activity to improve health?

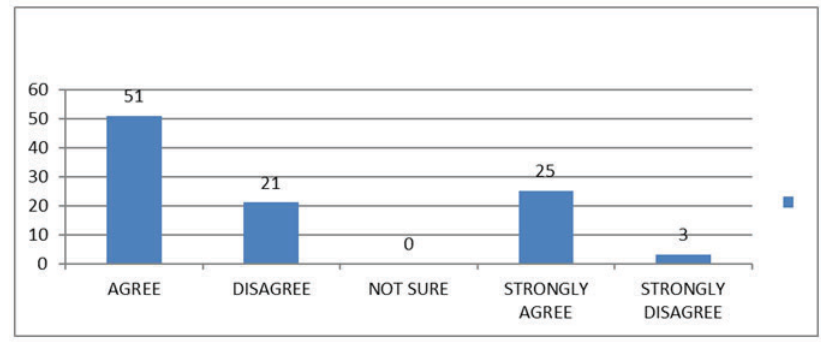

Table no 2 shows 51\% of the therapist agreed that taking stairs at work is enough physical active to improve wealth as shown

\section{TABLE NO 3}

Que 3: Half an hour of walking on ,most days is all the exercise that is needed for good health

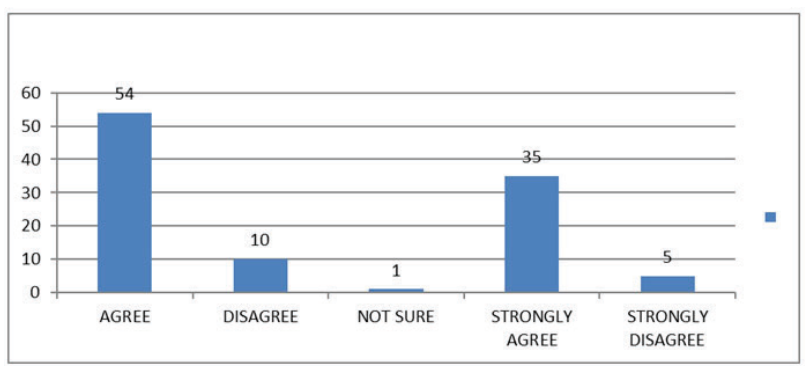

Table no 3 shows the results for half an hour of walking on most days is all the exercise that is needed forgood health has been agreed by $54 \%$ of physiotherapist

\section{TABLE NO 4}

Que 4: Exercise that is good for the health must make you puff and pant?

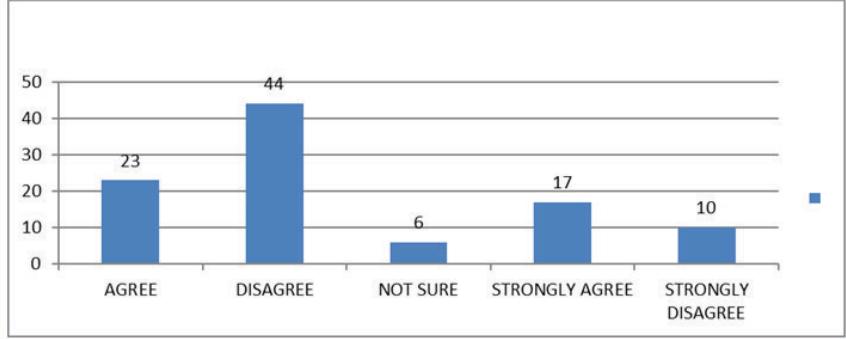

Table no 4 shows Exercise that is good for health must make you puff and pant has been disagreed by $44 \%$ of the subjects and $10 \%$ have strongly disagreed

\section{TABLE NO 5}

Que 5: Several short walks of 10 minutes each on most days is better than one

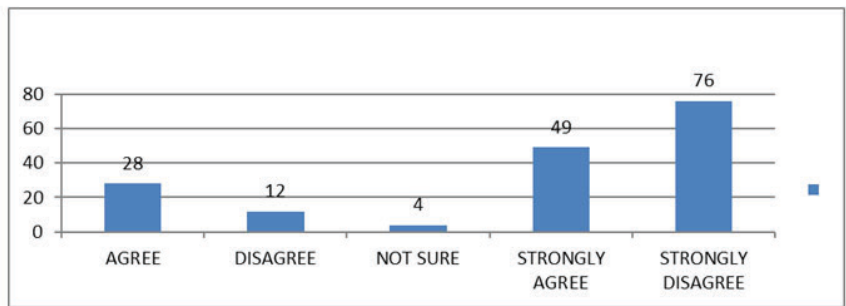

Table no 5 shows 44\% have agreed from the survey that several short walks of 10 minutes is better than one round of long walk per week for good health.

\section{TABLE NO 6}

Que 6: Discussing the benefits of a physically active lifestyle with patients is part of the physical therapist role?

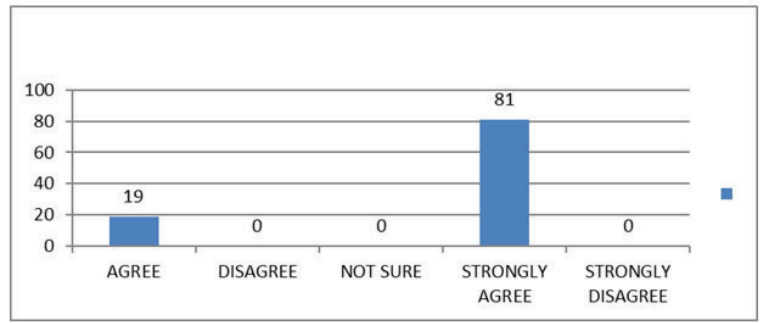


Table no 6 shows Discussing the benefits of physically active lifestyle with patients is a part of physical therapist role have been agreed by $81 \%$

\section{TABLE NO 7}

Que 7: Suggesting to patients ways to increase daily physical activity is part of the physical therapist role?

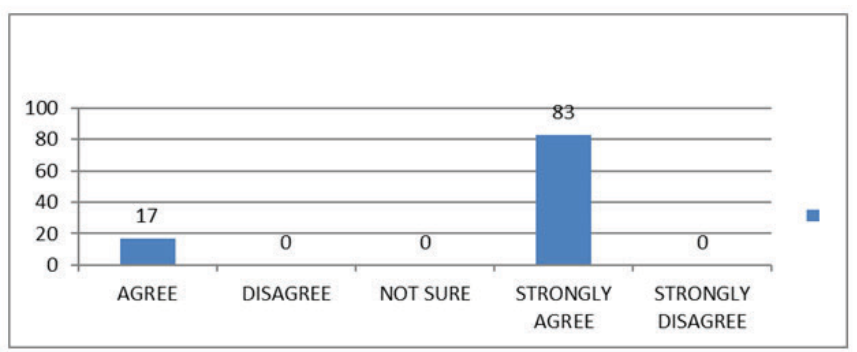

Table no 7 shows Suggesting patients ways to increase daily physical activity is a part of physical therapists role have been agreed by $83 \%$ of the subjects.

\section{TABLE NO 8}

Que 8: I feel confident in giving general advice to patients on a physically active lifestyle?

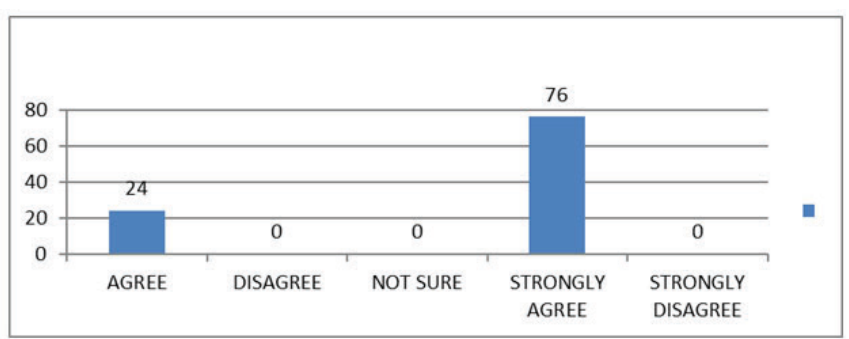

Table no 8 shows Only $76 \%$ felt confident in giving general advice to patients on physically active lifestyle.

\section{TABLE NO 9}

Que 9: I feel confident in suggesting physical activity specific physical activity programs for my patients?

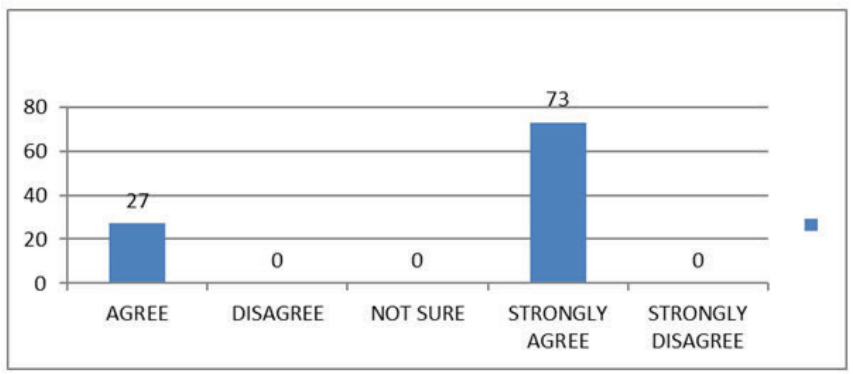

Table no 9 shows $73 \%$ of subjects were agreed to feel confident in suggesting specific activity programmes for their patients.

\section{TABLE NO 10}

Que 10: Physical therapist should be physically active to act as a role model for their patients?

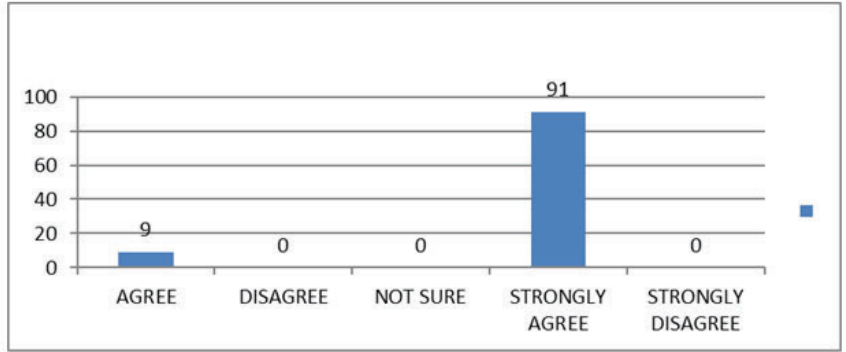

Table no 10 shows an overwhelming 100\% agreement was found for fact that physical therapist should be physically active to act as a role model for their patients of which $91 \%$ strongly agreed and $9 \%$ agreed.

\section{TABLE NO 11}

Que 11: A bout your own physical you think you are currently compared with other Indians of your age and sex?

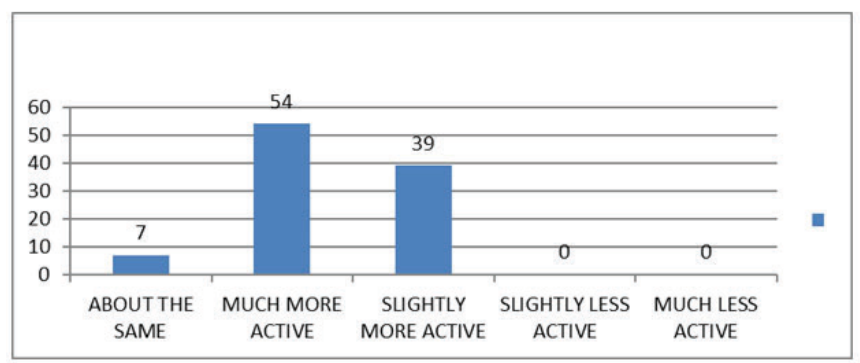

Table no 11 shows About own physical activity 54\% felt much more active when compared with other Indians of same age and sex. 39\% felt slightly more active and $7 \%$ about the same none of them reported with slightly less active or much less active.

\section{DISCUSSION}

The results of the current study is indicating that physiotherapist are determining promotion of physical activity in physical therapy settings thereby supporting our aim although the results are not similar among all the physical therapy practitioners thereby helping us to know the attitude of therapist 
towards physical activity in relation to patient and self is also determined thereby supporting both aims. Therapist encouraging patients to have physically active lifestyle is in itself indicative of making patients aware and also make them practice active lifestyle in their day to day life. Although therapist agreed $51 \%$ for taking stairs at work is sufficient physical activity for health improvements is indicative of fact that most of the places in urban areas are provided with lift facilities and it becomes really difficult for use of stairs due to time constraints.

It has also been agreed by overwhelming $81 \%$ of the therapist that discussing benefits of physically active lifestyle is part of physical therapist activity.This is very important because these are the machinery which are employed to bring about in cooperation of physically active lifestyle in day to day life of patients and also they are required to suggest the patients.

Various ways and means in improving as well as increasing daily physical activity and also they are responsible in giving general advice confidently to patients on active lifestyle .Moreover it is also note that therapist were feeling confident in suggesting specific activity programmes for their patients thereby emphasizing the fact that physical activities have to individually tailored depending upon the needs and requirements of individual patients so hence specificity for activity programmes can also come under the ambit of physiotherapy practice thereby making the physiotherapy a first hand practitioners for physical activities hence they can act as primary practitioners for physical activity promotion as well as physical activity implementation. This study is supported by LM Buffart, Hp Van der et al. ${ }^{3}$ who conducted a cross sectional survey study on general practitioners 'perceptions and practices of physical activity counseling in new south wales (Australia), he concluded that most increase in the proportion of general practitioners reporting high knowledge role perception and confidence in giving physical activity advice to patients occurred between 1997 and 2000 and remain unchanged thereafter, in 2007 general practitioners to give more physically activity advice. ${ }^{3}$ This is also supported by Debra Shirley, Hidde P et al. ${ }^{1}$ who conducted a study to determine knowledge, confidence, role perception, barriers. Feasibility and counseling practices of physical therapist and physical therapist students to promote physical activity for better health, he concluded that physical therapist practice appears to be an excellent avenue for promoting a physically active life style and could potentially play an important public health role. ${ }^{4}$

Walking is all the exercise that is needed for good health which is agreed by $54 \%$ of the therapist is indicating that walking could be implemented as a good home exercise programme as it is cheap and effective way of bringing about improvement of health and may be that is the reasons why most people undertake walking either in morning or evening depending upon their conveniencelt is also beennoted that exercise should not makeyou puff and pant or in other words exercise should be over exhaustive thereby emphasizing the fact that exercise have to be performed within the optimum level in order to have greater benefits if the subjects would have not been physiotherapist than the results would have differed because there is misnomer in general public that you have to exercise till exhaustion but in reality it is not.

It is alsobeen agreed from the survey that severalshort steps of walk is better than one long walk, and this subjective evaluation is in the Indian set up done by Qumran in the Indian set up which was objectively proved. Since the therapist are involved in implementation as well as promotion of physical activity there was also an agreement of $100 \%$ that physical therapist have to be physically active,hence it is required that the physiotherapist themselves should incorporate some formof physical activities in their own lifestyles in order to be physically fit. This is supported by Josephine Chau, Ben J. Smith et al. ${ }^{4}$ who conducted a study to examine recent trends in sufficient physical activity among new south wales adults aged 16 years and over he concluded that findings indicate that in recent years physical activity participation has began to increase and this increase occurred across population segments, the increases occurred especially in walking behaviors. ${ }^{5}$

The results obtained from comparisons of own physical activities with other counterparts of same age and sex most of the people felt , much more active or slightly more active or about the same to this may be attributed to the fact that age group was a relatively younger age group, if the subjects age group would have been 50 or more the results may have been slightly variant and would appear as slightly less active or much less active.

\section{CONCLUSION}

It is concluded that physiotherapist are basically responsible for encouraging patient for having physically activity and also suggest various means and measures to improve and enhance patients physical activity ,physiotherapy is a highly active field requiring self to be physically fit and also it is a growing profession and covering various fields of medical health. Therefore this study highlightens the fact that physical therapy not only involves administration of physical exercise but includes advices and means of physical activity promotion.

\section{Acknowledgement: None}

Conflict of interest: None

Financial support: None 


\section{REFERENCES}

1. Shirley D, Hidde P. et al. 'Physical Activity Promotion in the Physical Therapy Setting: Perspectives From Practitioners and Students' physical therapy.2010;90 (9) 1311-1322.

2. Haskell, William Lee et al. ' Physical activity and public health updated recommendations for adults from the American college of sport medicine and the American heart Association' med sci sports exerc.2007;39 (8);1423-34

3. LM Buffart, HpVan der ploeg et al. 'General practitioners 'perceptions and practices of physical activity counselling: changes over past 10 years Brj sports med 2009;43 (14):1149-53.

4. Josephine chau, Ben J. Smith et al. 'Recent trends in physical activity in new south wales 2008; 32(1); 82-85. 